Reinbold, A., Seppänen, O., Peltokorpi, A., Singh, V. and Dror, E. (2019). "Integrating Indoor Positioning System and BIM to Improve Situational Awareness." In: Proc. $27^{\text {th }}$ Annual Conference of the International. Group for Lean Construction (IGLC), Pasquire C. and Hamzeh F.R. (ed.), Dublin, Ireland, pp. 1141-1150. DOI: https://doi.org/10.24928/2019/0153. Available at: <www.iglc.net>.

\title{
INTEGRATING INDOOR POSITIONING SYSTEMS AND BIM TO IMPROVE SITUATIONAL AWARENESS
}

\author{
Ana Reinbold ${ }^{1}$, Olli Seppänen ${ }^{2}$, Antti Peltokorpi ${ }^{3}$, Vishal $\operatorname{Singh}^{4}$ and Erez Dror $^{5}$
}

\begin{abstract}
This paper presents the concept for the integration of Indoor Positioning System (IPS) and Building Information Model (BIM), and hypothesizes about the possible benefits of this integration to situational awareness and visual management in construction projects.

Literature review shows that the volume and quality of data enabling situational awareness during construction projects is increasing with the use of new technologies, such as indoor positioning systems and other applications of Internet of Things (IoT). However, these information streams have been used individually so far.

BIM as the interface integrating different streams of situational awareness information can result in better data-driven construction management and production. This study suggests that using BIM in 3D visualization of the indoor positioning of construction resources (workers, material, and equipment) enables visual management based on situation awareness on construction project activities. Better situational awareness of construction resources on-site based on visualization in BIM can improve the identification and elimination of waste and the identification of workflow interruptions, potentially permitting better planning and increasing productivity.

The study suggests further steps for empirical research to prototype the concept and validate it with industry partners and practitioners.
\end{abstract}

\section{KEYWORDS}

Lean construction, BIM, visual management, indoor positioning systems, information integration.

1 Doctoral Candidate, Department of Civil Engineering, Aalto University, Espoo Finland, +358 50431 2015, ana.reinbold@aalto.fi

2 Professor of Practice, Department of Civil Engineering, Aalto University, Espoo Finland, +358 50368 0412, olli.seppanen@aalto.fi

3 Assistant Professor, Department of Civil Engineering, Aalto University, Espoo Finland, +358 50371 6613, antti.peltokorpi@aalto.fi

4 Assistant Professor, Department of Civil Engineering, Aalto University, Espoo Finland, +358 50431 2015, vishal.singh@ aalto.fi

5 MSc graduate, Department of Civil Engineering, Technion IIT, Haifa Israel, +972 545961265 , erezdror@gmail.com 


\section{INTRODUCTION}

Construction problems are often tackled using outdated information. The lack of situational awareness in construction projects is related to information bottlenecks and the cost and time needed to collect and update data (Akinci, 2014).This situation leads to poor efficiency of the actions taken, waste of time and money to collect the information when it is needed, decision making about resources and time made within inappropriate timing and the reactive problem solve culture, so common during the construction phase (Dave et al 2008, Akinci, 2014).

Technology development is increasing the possibility to collect data automatically in the architecture, engineering and construction industry (AEC) through 3D laser scanning and photogrammetry, indoor positioning systems (IPS) and other applications of Internet of Things (IoT). These developments are increasing the volume and quality of data collected, but the different data streams have been used individually so far. This maintains the information silos which have been commonly identified in the construction industry (Dave et al. 2008).

Building Information Modelling (BIM) tools are increasingly used in the AEC industry to manage the design and construction phases of projects. Studies of the synergies between lean construction and BIM revealed that high quality information provided by information models can improve the flow of work on site (Sacks et al. 2010) and that building modelbased interfaces for visual representations of the construction project status can be applied effectively (Sacks et al. 2010).

Previous research on the integration of activities' status information and BIM for visual representation of the construction flow have been conducted with the test and implementation of the system called 'KANBIM' (Sacks et al. 2012) and with the creation and implementation of the commercial system VisiLean ${ }^{\circledR}$ (Dave 2013). Both systems were able to measure benefits of utilizing BIM as the interface to visualize activities' status.

A particularly interesting new technical tool from the perspective of lean construction are Indoor Positioning Systems (IPS). IPSs automate data collection on production resources and status using sensor technologies, and different types of sensors are being explored as Radio-frequency Identification (RFID) (Costin et al. 2012), Magnetic Field (Park et al. 2016), ZigBee (Lin et al. 2013), and Bluetooth Low Energy (BLE) (Olivieri et al. 2017; Dror et al. 2018). These technologies can enable real-time tracking and positioning of labour, material and equipment, and the information can be used to evaluate and visualize the flows of construction projects, improving the decision-making process at the operational, tactical, and strategic levels (Vasenev et al. 2014).

Visualised real time data collected from IPS have potential to increase the situational awareness in construction projects and enable pro-active management regarding resources placement. The development and research of systems to enable such visualization is ongoing (Park et al 2016, Dror 2018) and have been applied for first responders in accidents situations (Lee, 2009) integrating BIM and Global Positioning Systems (GPS). However, the use of IPS during production phase decision making in construction sites remains unexplored. This research focuses on the concept of integrating and visualizing data collected from IPS during construction projects in a BIM environment. Possible benefits 
to production control of construction projects are explored. The research method consists of the review of existing literature on IPS, BIM, visual management and situational awareness to propose the integration and following empirical studies to implement and validate the concept.

\section{SITUATIONAL SWARENESS AND BIM}

\section{Situational Awareness and Visual Management}

The definition of Situational Awareness (SA) originated from the military operations and was defined as "the perception of the elements in the environment within a volume of time and space, the comprehension of their meaning and the projection of their status in the near future" (Endsley 1995). SA is categorized into three hierarchical phases: Perception of elements in current situation; Comprehension of current situation; Projection of future status.

The term was first applied to construction projects focusing on safety management (Gheisari et al. 2010) but can also be applied to construction projects as a whole. Increasing the situation awareness during the production phase has the potential to allow better and more pro-active decisions about control actions both from the project managers and the workers.

Important tools to increase the situation awareness include improving communication and increasing the transparency of the processes in the construction sites. To achieve this, the use of visual communication and visual management (VM) tools has increased and successful cases of implementation have been documented (Tezel et al. 2011). Visual Management is an element of the Toyota Production System (Liker 1997; Formoso et al. 2002) and due to this, often associated with Lean Construction (Koskela 1992).

With the increasing dissemination and use of BIM technologies during construction projects, and these becoming the platforms to create and share 2D and 3D drawings, and other visual representations, like quantities sheets, structure details, and project planning, the integration of VM with BIM appears to be a logical development.

The lack of updated information in construction projects and the information silos are problems that could be solved by using BIM for integrating information connecting the real world and internet of things (IoT). This enables system-system, system-human and human-system communication. These multiple channels have as their objective capturing data at the right time and delivering it to the right person at the right time (Dave et al. 2015).

This potential has also been perceived by other industries and users from outside the construction industry. Development of the integration between BIM and GPS for use by first responders (fire brigades and rescue teams) in case of accidents, has already been explored (Lee et al. 2009) showing benefits to the situational awareness of the team when applying tracking in combination with visualization.

Visual Management applications aim to provide easy access to information, enabling the process participants to take the necessary actions with the correct timing (Liker, 1995; Koskela, 2001). BIM has the potential to be the platform used for VM in construction, and this potential has already been noticed by researchers and practitioners. Two researches aiming to develop this integration and understand how BIM based VM could improve 
construction management have been published, namely the KanBIM ${ }^{\mathrm{TM}}$ Workflow Management System (Sacks et al. (2012) and VisiLean Dave et al. (2011). These systems were reviewed during this study to understand how the integrations have previously been executed and which results were measured.

The work from Park et al. (2016) integrated BLE and motion sensors with visualization applying BIM. The research was focused in the accuracy and the feasibility aspects of the implementation and it did not cover aspects such as the benefits of implementation in construction or the impact on the situational awareness of the ones using the application.

The existing systems integrating VM and BIM are presented next, listing and describing the ones involving manual input information first followed by the one involving IPS data collection but is not integrated with BIM

\section{EXISTING SYSTEMS}

\section{KanBIMTM}

The research of Sacks et al. (2012) started from the perception of the potential of BIM visualisation capabilities and the effectiveness of information systems in supporting the monitoring and changing of workflows. From the hypothesis that a BIM based workflow information system could be applied by construction crews for pull workflow strategies, the research developed and tested a prototype management information system to support lean workflow in construction sites.

The system is based on the Kanban cards as visual tools to pull work flow. It consists of cards with colour codes symbolizing the work status. The worker places the cards in a visible area to inform the workers from previous tasks if the work flow can continue, and the next workers if the task is concluded (green card), or was interrupted (red card), for example. The objectives are that all the workers involved in the workflow can visualise the cards and communicate efficiently any interruptions of flow and work status among themselves and to the supervisors.

\section{VisiLean}

Dave (2013) discussed that while lean construction concepts tackle the problems of construction processes, BIM presents solutions to model the construction projects and overcome the limitations of the 2D Computer Aided Design (CAD) representations. Based on these and the positive results of implementing BIM and Lean simultaneously, the author proposed "VisiLean", which is a management system that uses BIM as a visual platform together with lean concept of pull flow scheduling in construction projects.

The integration with the BIM model enables the representation of operations in an identified location and their progress. A series of visual management tools is applied to enable the easy identification of the current status of the operations. The task status, for example, can be marked as started or stopped, and colours are used to highlight this status. Also a poka-yoke, mistake-proof, approach was integrated in VisiLean by making it impossible to change the status of operations that have not yet started.

The researches from Dave (2013) and Sacks et al. (2012) were able to present the positive results of integrating data collection about production and planning with BIM technologies by integrating visual management tools and real time visualisation through 
the building models. However, both products, KanBIM ${ }^{\mathrm{TM}}$ and VisiLean rely on manual input of information, the first one on the input of the production teams about tasks progress and constraints and the second one on the input of the planning and controlling teams about tasks status. Manual input is required because at the time of these systems, the automated methods of data collection, such as IPS, were not yet mature enough from implementation.

\section{bKan}

The research of Dror (2018) proposed a different approach for visualizing project status and improving situational awareness. The research focused on creating a complete solution for information flow by creating data regarding resource location, and analysing and visualizing it.

Using BLE sensors and a developed application, project resources such as labour and material were monitored automatically. The data collected was transferred to a cloud based data analysis engine that then returned a visual status of resource location using a mobile interface heat map. The heat map was continuously updated automatically.

The researchers found that in a mobile interface it was difficult to visualize the project status using a 3D BIM model due to resolution issues, and therefore decided to visualize the information using 2D presentation: Building view (elevation) and in floor plan view.

After testing the platform created in real construction sites it was found that location monitoring using BLE beacons is a feasible solution that enables automatic project status update and analysis of movement patterns in order to assess wastes in the construction process. It was also noticed that even raw data that is presented to construction site managers can be very beneficial to their decision making process and save them a great amount of time.

The first systems have gaps related to the data collection that is not automated and depends on human input, which can present issues that goes from the simple human error to the costs of human data entry. The third system would eliminate the manual data entry, automating the data collection through the application of BLE's but this system does not include an integration with BIM models and the visualization using such tools. It utilizes 2D floor plans and elevations in the visualization of the BLE data.

Our research aim to cover the presented gaps, collecting data from the BLE systems in an automated manner and enabling the use of BIM to visualize the resources locations inside the construction site.

\section{INTEGRATING BIM AND IPS}

We propose the integration of automatically collected indoor positioning data of construction resources with BIM models as visual management tool to increase situational awareness in construction projects.

The technological advances in collecting real time data in construction projects are increasing the quantity and quality of data available. The IPS technologies, enable the tracking of construction resources in real time.

With the use of these sensors it is possible to collect in real time data regarding the location of resources in the construction site, the movement of workers and materials during production and the total time a worker spent in a certain location. It is possible to 
collect data about different resources locations using the IPS. However, just based on the position information it is not possible to infer which tasks the resources were working on or to ensure that all the needed for executing a task are in the right place at the right time. The association of the IPS data collection with other technologies, such as monitoring cameras can tackle this deficiencies, but they are not the scope of this BIM and IPS integration.

Linking the data with planning information will make it possible to visualize if the workers and material are in the planned position where required by their next task, and to detect any deviations faster than when using status update data produced weekly or at the end of day. Thus, the availability of data regarding materials and workers in real time can provide the construction team with more reliable information on the project status during the production.

Although massive data collection is now feasible, the different data streams and repositories continue to have poor connections and use different platforms to retrieve the information, contributing to the maintenance of information silos and multiplicity of information systems that are not connected or interoperable.

This research proposes that the BIM platforms could play a key role in forming situational awareness in construction projects, centralizing the different streams of data and becoming the reliable source of information during construction projects as depicted in Figure 1.

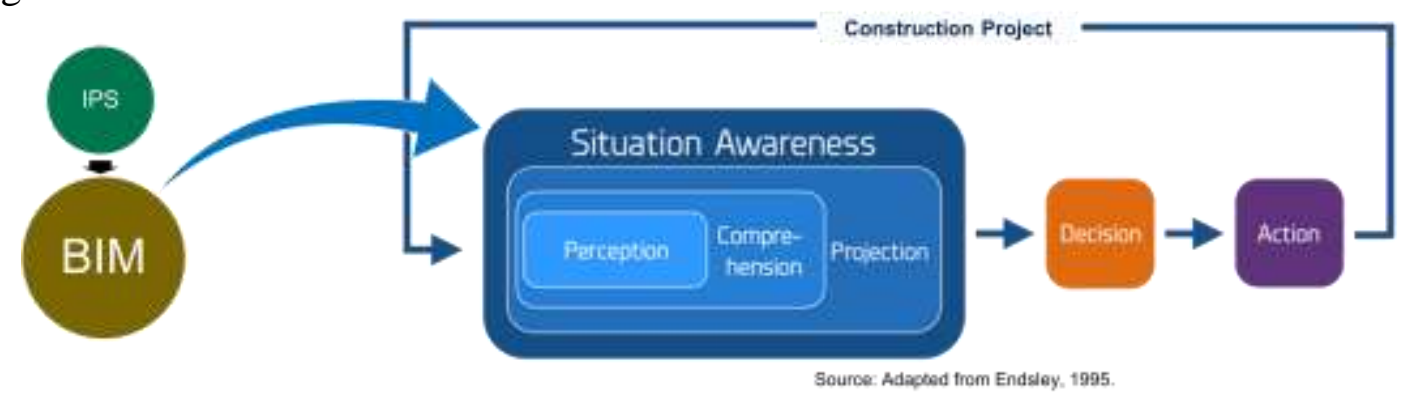

Figure 1: BIM as the Key Interface for Situational Awareness in Construction Projects

The integration of BLE data with BIM aiming a real time visualisation of workers, materials and equipment in construction can constitute a situational awareness tool to leverage the decision making for the construction project teams. It can enable:

- Visualization of planned locations of resources and their actual location, supporting the identification of plan deviations;

- Tracking of resources availability (workers, materials and tools) in the location of the task, enabling to take corrections regarding lack of resources in real time;

- Identification of work-in-progress locations, and comparing it with the planned and agreed work to be in progress;

- Analysis of frequency and intensity of workers and materials movements, which can allow a better understanding of the causes of waste and non-value adding activities.

The concept map of the integration is presented in Figure 2. 


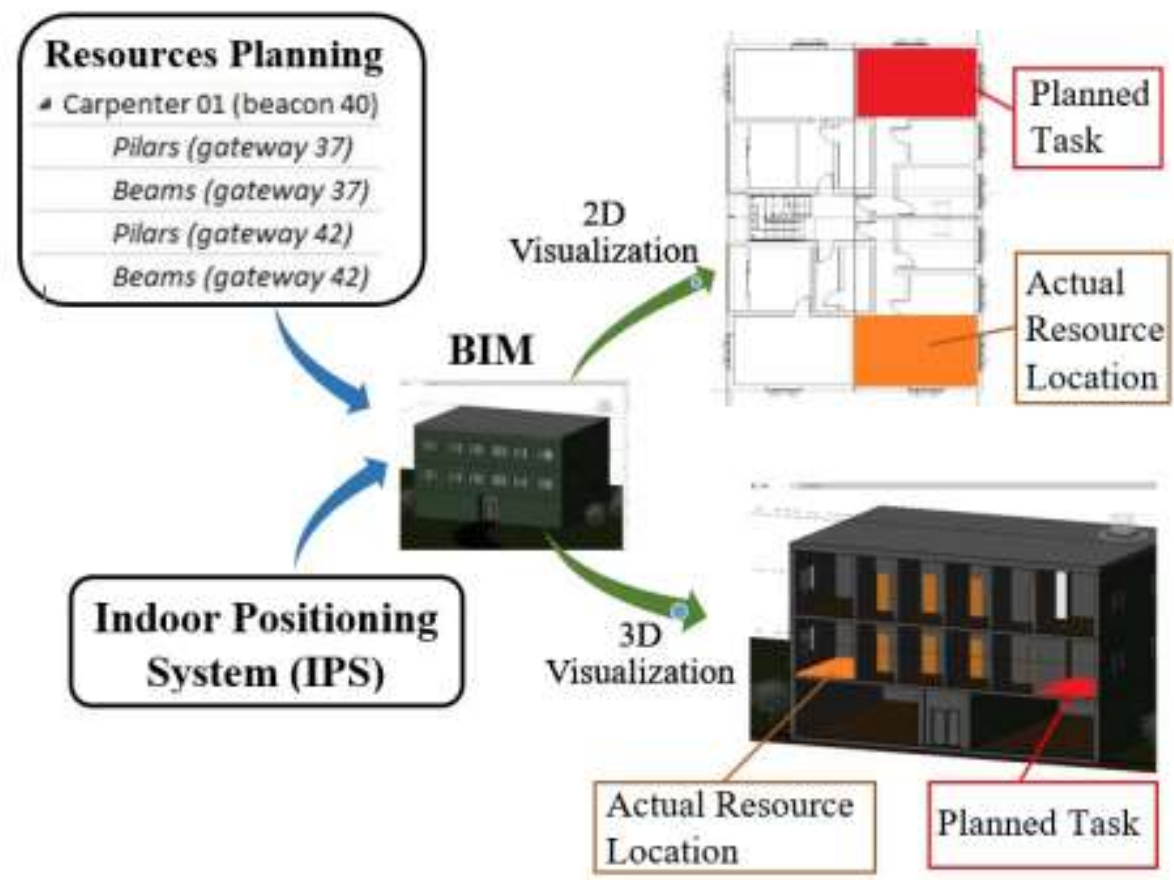

Figure 2: Concept Map of integrating BIM and IPS

\section{ETHICAL ISSUES RELATED TO LABOUR TRACKING}

Tracking and monitoring the movements of human resources arises important ethical issues that are aligned with the information technology ethical issues framework created by Manson (1986) with the categories of privacy, accuracy, property and accessibility. The integration of IPS data and possible visualizations with BIM must ensure to the tracked resources that their data will be handled maintaining their privacy and dignity and that the data is used for productivity improvement purposes and will not be misused or applied in detrimental actions against the employees.

The early involvement of the workers in development should be targeted and fully clarification on how workers will be tracked and which information will be collected must be made available. Early involvement of trade unions in the research can be an important tool to avoid any misunderstandings and assure the human resources participation. Informed consent should be given by the human resources to be tracked and the data ownership and the freedom to stop the tracking at any moment have to be clearly expressed. Uninformed tracking or tracking without consent is against ethical guidelines of research and any research requiring such methods should go through an extensive IRB approval process. In commercial implementation, it is likely that a joint agreement by the employer and employee unions should be made before large scale implementation.

\section{FURTHER STEPS FOR EMPIRICAL RESEARCH}

The integration of IPS data with BIM models is a starting point when aiming to facilitate the information retrieving and visualisation by construction project teams. The early future 
steps concern the validation of the concept with industry partners and practitioners about how to display the information and possible interactions with BLE data, schedule and BIM model.

Since data visualisation can be executed in the $2 \mathrm{D}$ or $3 \mathrm{D}$ format and the use of dashboards to analyse worker and material movements and task production rates are possible, the feedback of industry will support the validation of the visualisation means to be adopted. The following stage is the prototyping of systems and validation, which can be conducted through a pilot project.

After the validation of the prototype, implementation in real case studies should be conducted to evaluate whether the IPS visualisation increases the situational awareness in the construction projects, and whether it enables better decision making and identification of resource and movement waste during projects. The application in case study projects should take place also to find improvement opportunities on the visualisation criteria and to measure if the availability of the IPS information and its integration with BIM impact the situational awareness in construction projects.

\section{CONCLUSIONS}

By combining IPS and BIM, this study has indicated the potential of BIM for situational awareness in construction. Improved situational awareness can enable to perceive the real time picture of the situation on the ongoing project when it comes to resources location and availability, real value adding time spent in the production processes and adherence of planning and production. This information support the project management and the workers. The first, when decisions are made regarding late tasks, mobilization or demobilization of workers, material disposition and equipment availability, for example, more actively during the production control process, and not with the after problem correction approach. The second, providing information about the process and the production flow enabling better decisions about which place have all the resources needed for the tasks and where to work next.

As a conclusion, new technological developments related to automated data collection opens up new potential to be explored related to applying BIM in construction projects as a visual tool to increase situational awareness, and as an information and knowledge sharing platform.

\section{REFERENCES}

Akinci, B. (2014). "Situational Awareness in Construction and Facility Management". Frontiers of Engineering Management DOI 10.15302/J-FEM-2014037

Costin, A, Pradhananga, N., and Teizer, J. (2012). Leveraging passive RFID technology for construction resource field mobility and status monitoring in a high-rise renovation project. Automation in Construction, 24, 1-15.

Dave, B. \& Kubler, S. \& Pikas, E. \& Holmström, J. \& Singh, V. \& Främling, K. \& Koskela, L. 2015. "Intelligent Products: Shifting the Production Control Logic in Construction 
(With Lean and BIM)". Proc. 23rd Ann. Conf. of the Int'1 Group for Lean Construction. Perth, Australia, 29-31 July

2015. 10.

Dave, B. (2013). "Developing a Construction Management System Based on Lean Construction and Building Information Modelling" PhD Diss., Univ. of Salford.

Dave, B., Boddy, S., Koskela, L., (2011). "VISILEAN: Designing a Production Management System with LEAN and BIM" .In: Proc. 19th Ann. Conf. of the Int'1 Group for Lean Construction, Lima, Peru, July 13-15.

Dave, B., Koskela, L., Kagioglou, M. and Bertelsen, S., (2008). "A critical look at integrating people, process and information systems within the construction sector" .In: Proc. 16th Ann. Conf. of the Int'l Group for Lean Construction, Manchester, UK, July 16-18.

Dror, E. (2018). "Improving information flow in construction projects using real-time monitoring and information visualization", MSc Thesis, Technion IIT.

Endsley M.R. (1995) "Measurement of situation awareness in dynamic systems, Human Factors", Vol. 37, No. 1, 65-84

Formoso, C. T., Santos, A. D. and Powell, J. (2002). "An Exploratory Study on the Applicability of Process Transparency in Construction Sites". Journal of Construction Research, 3(1), 35-54

Gheisari, M., Irizarry, J and Horn, D (2010) "Situation awareness approach to construction safety management improvement". In: Egbu, C. (Ed) Procs 26th Annual ARCOM Conference, 6-8 September 2010, Leeds, UK, Association of Researchers in Construction Management, 311-318.

Koskela, L. (1992), "Application of the New Production Philosophy to Construction", Technical Report, Department of Civil Engineering, Stanford University, Stanford, USA.

Koskela, L. (2001). “On New Footnotes to Shingo". In Proc. of the 9th Ann. Conf. of the Int'l Group for Lean Construction (IGLC), Singapore, Singapore.

Koskela, L., \& Howell, G. (2001). "Reforming project management: The role of planning, execution and controlling". Proc. of the 9th Int'l Group for Lean Construction Conf., (IGLC 9), Kent Ridge Crescent, Singapore, 6 - 8 August 2001.

Lee, M.D.E. van der · Ven, J.G.M. van de · Rijk, R. van · Bras, R.(2009) "Situational Awareness for first responders : Evaluation of the BIMS field trial". International Conference on Technologies for Homeland Security - HST '09, 11-12 May 2009, Waltham, MD, USA, 524-528

Liker, J. (1997). "Becoming Lean: inside stories of US manufacturers", productivity press, Portland / OR.

Liker, J. K., Ettlie, J. E. and Campbell, J. C. (1995), "Engineered in Japan: Japanese Technology Management Practices", Oxford University Press, New York, USA.

Lin, P., Li, Q., Fan, Q., and Gao X. (2013). "Real-time monitoring system for workers' behavior analysis on a large-dam construction site". International Journal of Distributed Sensor Networks, 9(10), 509423.

Mason, R. O. (1986). "Four Ethical Issues of the Information Age." MIS Quarterly. 
Olivieri, H., Seppänen, O. and Peltokorpi, A. (2017). "Real-Time Tracking of Production Control: Requirements and Solutions" In: 25th Annual Conference of the International Group for Lean Construction. Heraklion, Greece, 9-12 Jul 2017. pp 671-678.

Park, J., Marks, E., Cho, Y. K., and Suryanto W. (2016). "Performance test of wireless technologies for personnel and equipment proximity sensing in work zones". Journal of Construction Engineering 654 and Management, 142(1), 04015049.

Park, J.,Cho, Y., and Ahn, C.(2016). "A Wireless Tracking System Integrated with BIM for Indoor Construction Applications." Construction Research Congress 2016: pp. 2660-2668. Doi: 10.1061/9780784479827.265

Sacks, R., Barak, R., Belaciano, B., Gurevich, U. and Pikas, E.(2012) " KanBIM Workflow Management System: Prototype implementation and field testing". Lean Construction Journal 2013 pp 19-35

Sacks, R., L. Koskela, B. Dave and R.L. Owen (2010). "The interaction of lean and building information modelling in construction." Journal of Construction Engineering and Management 136 (9): 968-980.

Sacks, R., Radosavljevic, M. and Barak R. (2010). "Requirements for building information modelling based lean production management systems for construction." Automation in Construction 19(5): 641-655.

Tezel, A. (2011). "Visual Management: an exploration of the concept and its implementation in construction". PhD, University of Salford

Vasenev, A., Hartmann, T., and Doree, A. G. (2014). A distributed data collection and management 665 framework for tracking construction operations. Advanced Engineering Informatics, 28(2), 127-137.

Zhao, J., Seppänen, O., Peltokorpi, A. and Badihi B. (2018). "Real-time Resource Tracking on Construction Site: Implementation Practice and Use Cases in Different Projects". Proc. Of the $17^{\text {th }}$ Int'l. Conference on Computing in Civil and Building Engineering, Tampere, Finland, 5-7 June 2018. 